\title{
A review of current European treatment guidelines for migraine
}

\author{
Fabio Antonaci - Cezar Dumitrache • \\ Ilaria De Cillis • Marta Allena
}

Received: 8 October 2009/Accepted: 21 November 2009/Published online: 18 December 2009

(C) Springer-Verlag 2009

\begin{abstract}
Migraine is one of the ten most disabling disorders worldwide, and despite recent developments in the management of migraine, it remains underdiagnosed and undertreated. Guidelines for the management of migraine aim to improve the quality of patient care and to assist professionals in decision making in relation to the overall healthcare process. Most European countries have published national clinical practice guidelines for migraine treatment. These guidelines need to be kept up-to-date with the most recent best clinical evidence and therapeutic strategies to ensure their optimal use to improve health outcomes. The aim of this review is to compare the English language guidelines available across Europe, analyzing differences and similarities, in order to provide a general overview to assist in assessing whether a European consensus on migraine treatment can be achieved.
\end{abstract}

Keywords National guidelines - Migraine management · Stratified care $\cdot$ Stepped care

F. Antonaci $(\bowtie) \cdot$ I. De Cillis

University Centre for Adaptive Disorders and Headache

(UCADH), Pavia, Italy

e-mail: fabio.antonaci@unipv.it; neuronet@libero.it

F. Antonaci · I. De Cillis

Headache Medicine Centre, Policlinic of Monza, Monza, Italy

C. Dumitrache

Department of Neurology, University Emergency Hospital

of Bucharest, Bucharest, Romania

M. Allena

Headache Unit, IRCCS “C. Mondino Foundation”, Pavia, Italy

\section{Introduction}

Clinical practice guidelines are defined as 'systematically developed statements to assist practitioner and patient decisions about appropriate health care for specific clinical circumstances' [1]. Guidelines are not intended to be didactic, but to provide guidance to improve the quality of care and of clinical decision making. Indeed, guidelines attempt to put evidence into clinical practice, and it is believed that practice guidelines can improve the quality, appropriateness and cost-effectiveness of healthcare, as well as serve as educational tools $[2,3]$.

Numerous clinical practice guidelines for the treatment of migraine have been published (Table 1). These guidelines aim to provide strategies to physicians for the management of migraine, and encompass accurate diagnosis according to the criteria of the International Headache Society (IHS) classification (First and second edition) $[4,5]$, and appropriate acute and prophylactic intervention, follow-up and referral for the general practitioner, and specialist care when needed. Some of the guidelines developed were based on the first edition of the IHS classification in 1988 (France, 2004; Italy, 2001; Denmark, 1998 and Netherlands 1997), [6-9] while the others were based on the second edition of the IHS classification (2004) (Scotland, 2008; Switzerland, 2008; Finland, 2008; United Kingdom [UK], 2007; Spain, 2007; Romania, 2006; Croatia, 2005) [10-16].

There are several national headache guidelines published either in English (Italy, France, Croatia, UK, Scotland and Denmark) or in other languages (Switzerland, Spain, Romania, Hungary, Netherlands and Finland). It is also noteworthy that some countries, such as Croatia, and The Netherlands, have published updated guidelines in 2007 and 2008 in their own language [17, 18]. 
Table 1 Comparison between European and national migraine guidelines: differences and similarities

\begin{tabular}{|c|c|c|c|c|c|c|}
\hline Country and year of publication & Language & Type of headache & Children & $\begin{array}{l}\text { Pregnancy } \\
\text { and lactation }\end{array}$ & $\begin{array}{l}\text { Non-drug } \\
\text { intervention }\end{array}$ & $\begin{array}{l}\text { IHS } \\
\text { criteria }\end{array}$ \\
\hline EHF (2007) [22] & English & Migraine, TTH, CH, MOH & Yes & No & Yes & 2004 \\
\hline EFNS (2006) [19] & English & Migraine, $\mathrm{CH}$, TACs & Yes & Yes & No & 2004 \\
\hline UK (2007) [13] & English & All primary headaches & Yes & Yes & Yes & 2004 \\
\hline Scotland (2008) [10] & English & All primary headaches & No & Yes & Yes & 2004 \\
\hline Croatia (2005) [16] & English & All primary headaches & No & Yes & Yes & 2004 \\
\hline Croatia (2008) [17] & Croatian & NU & NU- & NU- & NU- & \\
\hline Switzerland (2008) [11] & French & Migraine, TTH, CH, MOH & Yes & Yes & Yes & 2004 \\
\hline Finland (2008) [12] & Finnish & Migraine & Yes & Yes & NU- & 2004 \\
\hline Spain (2007) [14] & Spanish & Migraine & Yes & No & Yes & 2004 \\
\hline Romania (2006) [15] & Romanian & All primary headaches & No & No & Yes & 2004 \\
\hline The Netherlands (1997) [9] & Dutch & NU & NU & NU & NU- & 1988 \\
\hline The Netherlands (2007) [18] & Dutch & NU & NU & NU & NU & 2004 \\
\hline France (2004) [6] & English & Migraine & Yes & No & Yes & 1988 \\
\hline Italy (2001) [7] & English & Migraine, $\mathrm{CH}$ & No & No & No & 1988 \\
\hline Denmark (1988) [8] & English & Migraine, TTH, CH & Yes & Yes & Yes & 1988 \\
\hline
\end{tabular}

TTH tension-type headache, $\mathrm{CH}$ cluster headache, $\mathrm{MOH}$ medication-overuse headache, $T A C s$ trigeminal autonomic cephalalgias, $N U$ not understood (local language)

Some countries have produced a single guideline for all primary headaches which includes migraine (UK, Scotland, Croatia, Switzerland, Romania), whereas in Denmark the guideline covers both migraine and tension-type headache, and in Italy it covers migraine and cluster headache. Spain and France, however, have produced guidelines specifically for migraine.

Most guidelines include a section dedicated to the treatment of migraine in children, with the exception of Italy, Scotland, Croatia and Romania. However, only the guidelines from the European Federation of Neurological Societies (EFNS) [19], UK, Scotland, Croatia, Switzerland and Finland include recommendations for migraine therapy during pregnancy and lactation.

In the most of the guidelines there is also incorporated a description of the recommendations for non-drug treatment, including behavioral and psychological techniques, considered an important part of the headache management.

In 2006, the EFNS published a report aimed at providing evidence-based treatment recommendations for migraine management [19]. The recommendations, which are recently updated [20], are based on scientific best evidence from clinical trials and on expert consensus by a number of task forces set up by the EFNS using the classification system of the second edition of the HIS. Non-pharmacological treatments and behavioral measures are not addressed in these guidelines.

In 2007, the three major international, non-governmental headache organizations in languages. The aim of this report is to provide a definitive update on the guidelines for the drug treatment of headache. It will focus on the four most common forms of headache which account for almost all headache-related burden and presentations to the physician. The target audience will be primary-care physicians, who are assumed to be non-experts. These guidelines recognize country differences in drug approval and availability, and offer different options where appropriate [22]. Collaboration with the World Health Organization (WHO), collaborated to create the 'Lifting the burden initiative: the global campaign to reduce the burden of headache worldwide' (LTB campaign) [21]. The 'European principles of management of headache disorders in primary care' is a crucial part of this work and it is currently being translated into different.

In this article, the national guidelines for migraine treatment across Europe are compared, taking into consideration only those guidelines published in English and, where possible, published according to the second edition of IHS classification criteria. Acute treatment and preventive therapy are analyzed separately. The final aim of this article is to provide a general overview to assist in assessing whether a European consensus on migraine treatment can be achieved.

\section{Migraine treatment}

Traditionally, the management of migraine is divided into acute and/or symptomatic strategies (to relieve headache attack) and preventive strategies (to reduce frequency, 
duration and intensity of the attacks). Non-drug treatment is included in almost all national guidelines.

\section{Acute treatment}

Different options are available to stop migraine attacks: acute, symptomatic treatment. According to recent clinical evidence, the common approach to treating a migraine attack is based on early intervention when the pain is still mild, which can result in shortening the time to achieve a pain-free response.

Acute therapies are generally divided into two categories: non-specific treatments, such as paracetamol (acetaminophen), nonsteroidal anti-inflammatory drugs (NSAIDs, including aspirin [23]), opioids and combinations of analgesics, these are usually the first choice for the treatment of mild or moderate migraine attacks; and specific anti-migraine treatments, including ergotamine and the triptans, including almotriptan, naratriptan, sumatriptan, zolmitriptan, etc., which are usually first-line drugs for the treatment of severe migraine attacks.

The optimum benefit of triptans is achieved when they are taken at the very onset of headache, whilst pain is mild or moderate intensity. They are ineffective if taken during the aura phase. Currently available guidelines vary regarding their recommendations for early triptan treatment and further clarification of the guidelines may be beneficial in relation to the timing of treatment. For example, specifying treatment timing based on clinical data, such as treating when the pain is still mild and within $1 \mathrm{~h}$ of onset. This was the conclusion from the well-controlled 'Act when Mild' study which demonstrated that treating migraine within an hour of onset when pain was still mild with almotriptan $12.5 \mathrm{mg}$ significantly improved patient outcomes [24].

Almost all guidelines consider ergotamine effective and favorable for the treatment of migraine due to its low relapse rate, but because of its poor tolerability and an increased risk that it might induce overuse headache, some guidelines recommended ergotamine as a second-line treatment (EFNS and Germany, Level B), while others do not recommend it at all (Scotland, Level A).

A key aspect of the guidelines is the type of approach recommended for the acute treatment of migraine.

\section{Stratified versus stepped care}

Some guidelines recommend a stepwise approach to the treatment of migraine [European Headache Federation (EHF), UK and Scotland]: initially acute attacks are treated with the safest, least expensive therapies and migrainespecific medication is only used if the initial treatment fails. Others guidelines recommend a stratified approach
(EFNS, Italy), which is based on severity of illness and matches the patient's needs to the characteristics of the migraine (severity, frequency, disability, symptoms, time to peak); this approach recommends migraine-specific drugs for severe attacks.

The arguments in favor of stepped care are that the treatment decision is simple, guidelines are more defined, and patients receive different treatment options in order to find the most appropriate one. However, the disadvantages are that the time until patients receive their optimal medication can be protracted, patients are not involved in the treatment decision and they may become lapsed consulters if they are not receiving effective medication. In the stratified management approach, patients are involved in the treatment decision and more will be exposed to migraine-specific treatment. However, possible disadvantages of stratified care are that clear and straightforward counseling about medication is needed, treatment choice requires careful consideration of clinical evidence, and patients may have unrealistically high expectations.

The question of which approach is the best is still unresolved. Some national guidelines within Europe do not specify the approach to be followed. For example, in the Croatian guidelines the choice of acute treatment is based on migraine characteristics and in Germany detailed information is supplied for each pharmacotherapeutic group, but neither state a preference for stepped or stratified care.

Lipton and colleagues [25] conducted a prospective study in which they showed that the stratified care approach provides the optimal clinical outcome, and a post hoc analysis suggested stratified care was associated with lower costs compared with other approaches [26]. Furthermore, Silberstein et al. [27] recommended stratified care with the use of triptans in patients who have moderate or severe migraine, or whose mild-to-moderate migraine responded poorly to NSAIDs, in an evidence-based guideline for the treatment of migraine.

It is possible that guidelines influence the chosen treatment strategy, and that prescriptions for migraine medication correlate with the availability of guidelines. Evaluating patterns of acute migraine management in the population is an important step to assess treatment according to guidelines and to improve the quality of care.

In the Maze study (migraine and zolmitriptan evaluation), MacGregor et al. [28], showed that analgesics were the most common treatment prescribed for migraine, and an average of only $10 \%$ of subjects were prescribed triptans; ranging from $3 \%$ in Italy to $19 \%$ in the USA. These data have recently been confirmed in studies performed in the same countries [29, 30]. The tendency to prescribe triptans more frequently in some countries, such as Germany and the USA, may be because triptans are the 
first-line recommendation for treating migraine in the German and American guidelines. However, one could speculate that the tendency to prescribe triptans more frequently in these countries may be that other countries do not have, or do not adhere to, national guidelines.

Although these data are not directly linked to the availability and use of guidelines, they do provide information on the proportion of prescriptions written for the different types of agent in different countries, and the available guidelines will have an effect on what is prescribed. However, the use of guidelines requires further consideration in terms of whether or not their availability influences treatment strategies, or if they can be used to modify physician behavior with respect to treatment and thus improve patient outcomes.

The target audience for guidelines generally involves primary care physicians (EHF, Switzerland) or neurologists/headache specialists (EFNS, Croatia, Italy, Romania), although in other countries they are intended for all healthcare professionals who manage headache (France, Scotland, Spain, UK). While many factors may be involved, it is possible that headache specialists are more aware of the guidelines available and this may influence their prescription choice. There may be a need to target guidelines to different audiences, or a need to ensure that guidelines are disseminated not just to specialists, but also to primary care physicians.

Moreover, from 2006 some triptans (naratriptan $2.5 \mathrm{mg}$ and sumatriptan $50 \mathrm{mg}$ ) were approved in the UK and Germany as over-the-counter (OTC) drugs. This availability might increase the use of triptans in clinical practice and may also encourage patients to treat their migraine symptoms earlier.

\section{Preventive treatment}

Migraine prophylaxis is a major component in the management of migraine. The aim is to reduce the frequency, duration or severity of attacks and conversely increase the effect of acute treatment. There are a number of different pharmacological classes of prophylactic anti-migraine drugs. The five most commonly used are: $\beta$-adrenergic blockers ( $\beta$-blockers: metoprolol, propranolol, atenolol, bisoprolol, nadolol, timolol), anti-epileptic drugs (valproic acid, topiramate,), calcium channel antagonists (flunarizine), tricyclic antidepressants (amitriptyline) and serotonin antagonists (pizotifen, methysergide).

Table 2 shows the drugs used for migraine prophylaxis in each European country, the differences between the recommendations as a first-line (A or 1), second-line (B or 2) and third-line choice ( $\mathrm{C}$ or 3 ), and those drugs with limited levels of recommendation (D or 4) along with their availability (for example flunarizine, a calcium channel antagonist, is not available in the UK and Croatia). Ideally, the drug should be chosen from the first-line recommendations, based more on the potential side effects and the patient's coexistent and comorbid conditions.

In general, guidelines propose $\beta$-blockers (propranolol and metoprolol), calcium channel antagonists (flunarizine), anti-epileptics (valproic acid, topiramate) and tricyclic antidepressants (amitriptyline) as first-line drugs for migraine prophylaxis. Bisoprolol, gabapentin, venlafaxine, naproxen, butterbur root, vitamin B2 and magnesium are second-line agents for migraine prophylaxis, because there is less evidence available to support their efficacy. The prescription of other treatments, considered as third-line choices, varies across the countries, based on their availability (i.e. methysergide or pizotifen), on the opinion of experts in the headache field or on differences in the interpretation of data from clinical trials (such as lamotrigine, cinnarizine, verapamil, diltiazem, nimodipine, nortryptiline, doxepin, imipramine).

For migraine prophylaxis in pregnancy, only magnesium and $\beta$-blockers (propranolol or metoprolol) are recommended, except in the UK where the lowest effective dose of amitriptyline is permitted. The Croatian guidelines recommend only non-pharmacologic therapy.

For migraine prophylaxis in children and adolescents, all guidelines recommend a $\beta$-blocker (propranolol) or flunarizine. Pizotifen (elixir) is available as an alternative, but only in the UK.

\section{Conclusions}

Guidelines are developed to assist the physician in making appropriate choices in the management and treatment of migraine patients. Numerous clinical practice guidelines for migraine treatment have been published in different countries. They are aimed at all doctors who manage headache, and so they need to be easily understood and should be included in physician training. To ensure their optimal use, guidelines need to be kept up to date, encompassing the most recent clinical evidence and therapeutic strategies, and effectively distributed, e.g., via headache society websites. The recent European guideline principles [20] are easy to use, and are being translated into local languages.

Because guidelines are needed to set recognizable and acceptable standards of good practice, their adoption in primary care should be encouraged. However, the presence of the different health care systems in European countries, explains the difficult to uniform guidelines across national borders.

Looking to the future, it is important to consider what approaches can be used to ensure optimal dissemination of 
Table 2 Summary of drugs recommended for migraine prophylaxis, with level of evidence for each European country

\begin{tabular}{|c|c|c|c|c|c|c|c|}
\hline Country & $\begin{array}{l}\text { UK } \\
\text { (lines of } \\
\text { recommendation) }\end{array}$ & $\begin{array}{l}\text { Scotland } \\
\text { (grades of } \\
\text { recommendation) }\end{array}$ & $\begin{array}{l}\text { Germany } \\
\text { (strength of } \\
\text { recommendation) }\end{array}$ & $\begin{array}{l}\text { Croatia } \\
\text { (rating of } \\
\text { recommendation) }\end{array}$ & $\begin{array}{l}\text { Spain } \\
\text { (levels of } \\
\text { evidence) }\end{array}$ & $\begin{array}{l}\text { France } \\
\text { (grading of } \\
\text { recommendation) }\end{array}$ & $\begin{array}{l}\text { Italy } \\
\text { (levels of } \\
\text { recommendation) }\end{array}$ \\
\hline
\end{tabular}

$\beta$-blockers

$\begin{array}{lll}\text { Metoprolol } & 1 & \mathrm{D} \\ \text { Propranol } & 1 & \mathrm{~A} \\ \text { Atenolol } & 1 & \mathrm{D} \\ \text { Bisoprolol } & 1^{\mathrm{a}} & - \\ \text { Nadolol } & & \mathrm{D} \\ \text { Timolol } & & \mathrm{D}\end{array}$

A

A

$-$

B

$-$

Ca channel blockers

Flunarizine NA

Cinnarizine

Verapamil

Diltiazem

Nimodipine

Anti-epileptic drugs

Valproic acid 2

Topiramate 2

Gabapentin 3

Lamotrigine -

Tricyclic antidepressants

$\begin{array}{ll}\text { Amitriptyline } & 1 \\ \text { Nortryptiline } & - \\ \text { Doxepin } & - \\ \text { Imipramine } & -\end{array}$

Others antidepressants

$\begin{array}{ll}\text { Venlafaxine } & - \\ \text { Fluoxetine } & 4 \\ \text { Paroxetine } & - \\ \text { Mirtazapine } & - \\ \text { NSAIDs } & \end{array}$

\section{Aspirin}

Naproxen

Ketoprofen

Miscellaneous drugs

Magnesium

Butterburr

Feverfew

Botulinum

toxin

Candesartan

Serotonin antagonists

\section{Pizotifen}

Methisergide

A

A
C
-

A

A

C

$-$

B
-
-
-

B

$-$

$-$

$-$

B

$-$

NR B

$-$

$\begin{array}{llll}\text { B } & 1 & \text { A } & 2 \\ \text { A } & 1 & \text { A } & 1 \\ \text { A } & 1 & \text { A } & 1 \\ - & - & - & - \\ \text { B } & 1 & \text { A } & 2 \\ - & - & \text { A } & -\end{array}$

$\begin{array}{llll}\text { A (NA) } & 1 & \text { A } & 1 \\ - & - & - & 2 \\ \text { B } & - & - & 2 \\ - & - & - & 3 \mathrm{a} \\ \text { B } & - & - & 3 \mathrm{a}\end{array}$

$\begin{array}{llll}\text { A } & 1 & \text { A } & 1 \\ \text { B } & 1 & \text { A } & 2 \\ \text { A } & - & \text { A } & 2 \\ \text { B } & - & - & 2\end{array}$

$\begin{array}{llll}\text { A } & 1 & \text { A } & 1 \\ \text { C } & - & - & 3 \mathrm{a}^{\mathrm{a}} \\ \mathrm{C} & - & - & 4 \\ \mathrm{C} & - & - & -\end{array}$

$-$

B

B

$-$

B

$\begin{array}{ll}- & 3 b \\ \text { A } & 2 \\ - & 4\end{array}$

B

2

NA not available, $N R$ not recommended, A or 1: first-line; B or 2: second line; C or 3: third line; D or 4: drugs with limited levels of recommendation, 3a: drugs with adverse events of slight or moderate intensity, 3b: drugs with uncertain safety or with complex indications for use (e.g. special diet) or important pharmacological interactions

${ }^{\text {a }}$ Better evidence is needed 
guidelines to the various audiences (e.g. specialists, primary care physicians), and whether specific organizations, including headache societies and/or congresses, would be most appropriate to facilitate distributing this information. The success of the dissemination strategy depends on what proportion of the target audience is reached, and what effect the information has on their behavior. Guidelines appear to have more status if they are issued by a recognized organization, or at an international level. Nevertheless, most guidelines need to be adapted at a local level and need to be continuously reviewed and updated by experts in the field.

In conclusion, although guidelines for the management of migraine are considered undoubtedly valuable in daily clinical practice, they need to be kept up to date and to be disseminated around European countries. Furthermore, several key questions need to be considered to ensure the optimal use and diffusion of guidelines for migraine management. (i.e., English translation).

Conflict of interest None.

\section{References}

1. Field MJ, Lohr KN (eds) (1990) Committee to advise the public health service on clinical practice guidelines, Institute of Medicine. Clinical practice guidelines: directions of a new program. National Academy Press, Washington, DC

2. Shaneyfelt TM, Mayo-Smith MF, Rothwangl J (1999) Are guidelines following guidelines? The methodological quality of clinical practice guidelines in the peer-reviewed medical literature. JAMA 281:1900-1905

3. Natsch S, van der Meer JW (2003) The role of clinical guidelines, policies and stewardship. J Hosp Infect 53(3):172-176

4. Headache Classification Committee of the International Headache Society (1998) Classification and diagnostic criteria for headache disorders, cranial neuralgias and facial pain. Cephalalgia 8(Suppl 7):1-96

5. Headache Classification Committee of the International Headache Society (2004) the international classification of headache disorders, 2nd edn. Cephalalgia 24(Suppl 1):1-160

6. Géraud G, Lanteri-Minet M, Lucas C, Valade D (2004) French Society for the study of migraine headache (SFEMC). French guidelines for the diagnosis and management of migraine in adults and children. Clin Ther 26(8):1305-1318

7. Gallai V, Sarchielli P, for the Ad Hoc Committee for the Diagnostic and Therapeutic Guidelines of Migraine and Cluster Headache (2001) Diagnostic and therapeutic guidelines for migraine. Italian Society for the Study of Headaches (SISC). J Headache Pain 2:S125-S129

8. Jensen K (1998) Guidelines for the management of headache. Danish Neurological Society and the Danish Headache Society. Cephalalgia 18(1):9-22

9. Quality-control committee of the Netherlands Society of Neurology (1997) Guidelines for diagnostics and treatment of chronic migraine headache recurrence without neurological abnormalities. Netherlands Society for Neurology, Utrecht, The Netherlands

10. Scottish Intercollegiate Guidelines Network (SIGN) The diagnosis and management of headache in adults. (Guideline No 107).
SIGN, Edinburgh, 2008. Available via http://www.sign.ac.uk. Accessed 10 Mar 2009

11. Société Suisse pour l'étude des céphalées (2008) Céphalées et algies faciales. Recommandations therapeutiques avec traitement des céphalées par le médecin de famille. Available via http://www.headache.ch/Therapieempfehlungen. Accessed 23 Mar 2009

12. Farkkila M (2008) Finnish current care guideline migraine. The working group set up by the Finnish Medical Society Duodecim and The Finnish Society of Neurology. Available via http://www.ehf-org.org/guidelines/Pages/EHFGuidelines.aspx. Finnish Current Care Guideline Migraine, Accessed 10 Jun 2009

13. British Association for the Study of Headache (2007) Guidelines for all healthcare professionals in the diagnosis and management of migraine, tension-type, cluster and medication-overuse headache, 3rd edn. Available via http://216.25.88.43/upload/NS_ BASH/BASH_guidelines_2007.pdf. Accessed 10 Mar 2009

14. Lainez JM, Castillo J, Gonzales VM, Otero M, Mateos V, Leira R, Pascual J (2007) Guia de recomendaciones para el tratamiento de la migrana en la practica clinica. Rev Clin Esp 207(4): 190-193

15. Stefanache F, Cuciureanu D (2006) The headache and cranial neuralgias. In: Bajenaru O (ed) Diagnosis and treatment guidelines in neurology. Amaltea, Bucharest, pp 140-195

16. Demarin V, Vukovic V, Lovrencic-Huzjan A, Lusic I, Janculjak D, Wilheim K (2005) Evidence based guidelines for treatment of primary headaches. Acta Clin Croat 44:139-183

17. Demarin V, Vukovic V, Lovrencic-Huzjan A, Lusic I, Janculjak D, Wilheim K, Zurak N (2008) Evidence based guidelines for treatment of primary headaches. Acta Med Croatica 62:99-136

18. Couturier EGM, Bomhof MAM, Gooskens RHJM, Keyser A, Mulleners WM (2007) Richtlijnen Diagnostiek en Behandeling Chronisch Recidiverende Hoofdpijn Zonder Neurologische Afwijkingen. Commissie Kwaliteit van de Nederlandse Vereniging voor Neurologie Werkgroep Richtlijnen Hoofdpijn. Available via http://www.neurologie.nl/uploads/136/1169/richtlijn_hoofdpijn_ versie_2008.pdf. Accessed 08 Jun 2009

19. Evers S, Afra J, Frese A, Goadsby PJ, Linde M, Sandor PS (2006) EFNS guideline on the drug treatment of migraine-report of an EFNS task force. Eur J Neurol 13(6):560-572

20. Evers S, Afra J, Frese A, Goadsby PJ, Linde M, May A, Sándor PS (2009) EFNS guideline on the drug treatment of migrainerevised report of an EFNS task force. Eur J Neurol 16(9):968-981

21. Steiner TJ (2004) Lifting the burden: the global campaign against headache. Lancet Neurol 3:204-205

22. Steiner TJ, Paemelaire K, Jensen R, Valade D, Savi L, Lainez MJ, Diener HC, Martelletti P, Couturier EG (2007) European Headache Federation; lifting the burden: the global campaign to reduce the burden of headache worldwide, World Health Organization. European principles of management of common headache disorders in primary care. J Headache Pain Suppl 1:83-47

23. Lampl C, Voelker M, Diener HCJ (2007) Efficacy and safety of $1,000 \mathrm{mg}$ effervescent aspirin: individual patient data metaanalysis of three trials in migraine headache and migraine accompanying symptoms. J Neurol 254(6):705-712

24. Goadsby PJ, Zanchin G, Geraud G et al (2008) Early vs. nonearly intervention in acute migraine-'Act when Mild (AwM)'. A double-blind, placebo-controlled trial of almotriptan. Cephalalgia 28:383-391

25. Lipton RB, Steward WF, Ryan RE Jr et al (2000) Stratified care vs step care strategies for migraine. The Disability in Strategies of Care (DISC) Study: a randomized trial. JAMA 284:2599-2605

26. Sculpher M, Millson D, Meddis D, Poole L (2002) Cost-effectiveness analysis of stratified versus stepped care strategies for acute treatment of migraine: the Disability in Strategies of Care (DISC) Study. Pharmacoeconomics 20:91-100 
27. Silberstein SD (2000) Practice parameter: evidence-based guidelines for migraine headache (an evidence-based review): report of the Quality Standards Subcommittee of the American Academy of Neurology. Neurology 55:754-762

28. MacGregor EA, Brandes J, Eikermann A (2003) Prevalence and treatment patterns: the global migraine and zolmitriptan evaluation Survey. Headache 43:19-26
29. Pavone E, Banfi R, Vaiani M, Panconesi A (2007) Patterns of triptans use: a study based on the records of a community pharmaceutical department. Cephalalgia 27:1000-1004

30. Bigal ME, Borucho S, Serrano D, Lipton RB (2009) The acute treatment of episodic and chronic migraine in the USA. Cephalalgia 29:891-897 